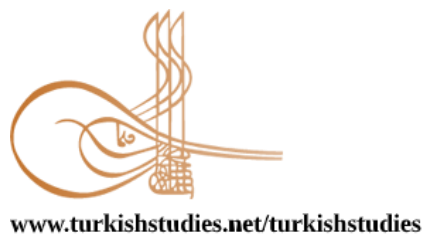

Turkish Studies

www.turkishstudies.net/turkishstudies

eISSN: $1308-2140$

TERNATIONAL

BALKAN

Sponsored by IBU

Research Article / Araştırma Makalesi

\title{
Covid-19 Pandemi Sürecinde Evde Uygulanan Yüksek Yoğunluklu Aralıklı Antrenmanlar Profesyonel Hentbol Oyuncularının Formda Kalmalarını Sağlayabilir mi?
}

\author{
Can High Intensty Interval Training Applied During The Covid-19 Pandemic Period Ensure That
} Professional Handball Players Stay In Form?

\author{
Murat Bilge $^{*}$ - Gökhan Deliceoğlu** - Özkan Işık ${ }^{* * *}$
}

\begin{abstract}
The purpose of the research is to show professional handballers that high-density exercises applied in the home environment are similar to aerobic capacity in the field environment. The research group is 16 national handball players with an average age of $24.67 \pm 5.71$ years, length of $186.69 \pm 6.40 \mathrm{~cm}$ and body weight $89.63 \pm 8.64 \mathrm{~kg}$. Polar clock was used to detect heart beat counts during exercises performed by handball players in the home environment. Five weeks of exercises of different intensity are divided into 4 different intensity exercise groups. Handball players recorded heart rate (HR) and perceived difficulty at the end of their workouts in the home environment. According to the findings, HRmax values in the field environment have a moderate relationship with some exercise Rating Perceived Exertion (RPE) values with MaxRPE, which is a high level of relationship with some exercise HR values of some exercise HR values of different densities. As a result, while the training HR values taken from handball players are planned to resemble the training load, it may be suggested that some training structures do not capture the target HR value, that RPE values taken from handball players are subjective, as well as verifying according to the HR value during training.
\end{abstract}

\section{Structured Abstract: Introduction}

Covid 19 pandemic sparked the 2019 New Coronavirus, formerly known as "2019 novel coronavirus (2019-nCoV) and the disease was officially named COVID-19 by the World Health Organization on February 11, 2020. Studies have shown that the virus that causes COVID-19 is mainly transmitted through the theme of respiratory droplets of an infected person. The COVID-19 outbreak has affected all areas of life, including sports (www.who.int).

\footnotetext{
* Doç. Dr., Kırıkkale Üniversitesi, Spor Bilimleri Fakültesi, Antrenörlük Eğitimi Bölümü Assoc Prof., Kirlkkale University, Faculty of Sport Sciences, Department of Coaching Education ORCID 0000-0002-1129-0563 muratbilge@gmail.com

** Doç. Dr., Kırıkkale Üniversitesi, Spor Bilimleri Fakültesi, Antrenörlük Eğitimi Bölümü Assoc Prof., Kirlkkale University, Faculty of Sport Sciences, Department of Coaching Education ORCID 0000-0003-2459-9209 deliceoglugokhan@gmail.com

*** Doç. Dr., Balıkesir Üniversitesi, Spor Bilimleri Fakültesi, Antrenörlük Eğitimi Bölümü Assoc. Prof. Ballkesir University, Faculty of Sport Sciences, Department of Coaching Education ORCID 0000-0003-2561-1695 ozkanisik86@hotmail.com

Cite as/ Atıf: Bilge, M. \& Deliceoğlu, G. \& Işık, Ö. (2020). Covid-19 Pandemi Sürecinde Evde Uygulanan Yüksek Yoğunluklu Aralıklı Antrenmanlar Profesyonel Hentbol Oyuncularının Formda Kalmalarını Sağlayabilir mi? Turkish Studies, 15(4), 1395-1407. https://dx.doi.org/10.7827/TurkishStudies.44318

Received/Geliş: 18 June/Haziran 2020 Accepted/Kabul: 27 August/Ağustos 2020 Checked by plagiarism software Copyright $(\mathrm{C}$ MDE, Turkey Published/Yayın: 30 August/Ağustos 2020 CC BY-NC 4.0
} 
Every stakeholder of the sport has been affected by this pandemic, from sportsman to members of the media. During the COVID-19 process, many sporting activities, including professional leagues, have been suspended to limit the rate of transmission of the virus. Even the Summer Olympics, the world's most watched sports event, have been postponed for a year. These and similar methods of protection have caused the public to stay in their homes, and professional athletes have been forced to stop their professional activities and reduce their work towards their physical structures (Eirale et al., 2020).

Professional athletes have applied for home exercises to maintain their form during this time they are under quarantine at home. This experience has been a first for them as well. Of course, home exercises are not expected to replace field work. But how close could get to physiological requirements?

Home exercises are usually designed with body weight exercises. In addition, body weight exercises were preferred because elite handball players could not be homogeneous in terms of sports equipment found in their homes. Exercise with body weight is based on the principle of using one's own body as a means of resistance without using external resistance such as weightlifting, bar or machine (Harrison, 2010). Typical body weight exercises include variations such as push-ups, step-by-step, sit-ups, crouching and traction. In short, any movement that does not apply to additional resistance to the body is considered a body weight exercise (ACSM, 2013).

In this context, the hypothesis of the research; "The effect of high intensity exercises applied to handball players at the professional level will be achieved in the home environment to some parameters in the field environment".

In the study, which we planned with the studies carried out in the field writing, the criteria specific to the structure of the hentbolun have shaped our study. The aim of the study in this context is to show professional handballers the similarity of high-density exercises applied in the home environment to aerobic capacity in the field environment.

\section{Method}

The research group is made up of 16 national handball players who play for Spor Toto Handball in the Turkish Men's Super League. Handball leagues were suspended on 18.03.2020 by the sports ministry. For this reason, athletes are given individual training programs that they can apply at home. Covid 19 pandemics closed parks and training pitches outside and the restrictions began, the home exercises were started as of April 6, 2020, the leagues were registered on May 12, 2020 and the data of the five-week period between the fiveweek period was collected as the season was terminated.

The trainings are divided into 4 different intensity workout intensity, lasting five weeks and 4 days a week. Handball players applied these exercises, which lasted 5 weeks in the home environment, according to the period given from low to high density. They recorded the degree of difficulty detected during and at the end of exercises of different intensitys given below. The HRmax values of the athletes were evaluated by the handball-specific 30-15 Intermittent Fitness Test, which is regularly performed during the season, and the athletes' depletion rate was considered maxify (Buchheit et, 2010). The S-800 Model Polar watch was used to determine the number of heart beats during exercises performed by handball players in the home environment. The Polar system consists of an HRM with bundled software (Polar Pro Trainer 5; PPT) which is used to derive HRV values. Wallen et al. (2012) compare the results from hand-corrected ECG data to this system, and conclude that traditional ECGs should be preferred as 'the Polar system did not identify errors satisfactorily, or return valid values of HRV for certain groups". A 6-20 degree Borg scale was used to determine the degree of detection difficulty.

For the procedure of the HRmax and RPE, the HR and RPE values obtained from different training loads from the handball players who make up the research group were analyzed primarily by shapiro wilk test and regression analysis was performed if normality hypotheticals were provided. The handball players' age, height length and body weight characteristics were obtained from the descriptive statistics. SPSS 25.0 package program was used for statistical analysis. $\mathrm{P}<0.05$ received for level of significance 


\section{Finding and Discussion}

Maintaining physical capacity is a fundamental requirement for the athlete. In particular, for team sports athletes, aerobic strength and muscle strength are a fundamental prerequisite for maintaining performance that maintain a good level of both. Training physiological adaptation is a reversible process. Indeed, many aspects of physiological adaptation have been lost during long-term inactivity (Mallo, 2015). Speed and maximum strength are loss for greater physical capacity than durability and strength continuity. Overall, total inactivity is considered to be a general loss of up to $10 \%$ for each week (Varandas et al., 2017).

In the study, it is observed that interval studies within the scope of the low rate of this lack of training have created warnings, especially in the effects of the HRmax obtained in the field environment.

After the pandemic period, which will be considered a similar process to the transition period, it is very important that players maintain their fitness levels to tolerate a rapid increase in the frequency and intensity of training, while at the same time trying to minimize the risk of injury (Gabbett, 2007). In the study, which supports this literature, it was determined that the effect of high-pulse training satisousin in the athlete, in particular, that rpe values do not match the training load.

It is stated that high density aerobic capacity (VO2max) causes a significant decrease in high density aerobic capacity (VO2max) in 20 days or more. For this reason, after the off-season, athletes may have difficulty in tolerateing high training volume and intensity especially in the first weeks of the season (Silva et al., 2016). Hansen et al. (2018) noted that in addition to the recommendations for a $60 \mathrm{~min}$ load that should be considered in cardio-style exercises, the work coincides with $80 \%$ of HR (McMullen et al., 2018) training intermittent or intermittent training in which both aerobic and anaerobic lactic acid system is dominant (Dufour et al., 2006; Billat et al., 2000; Laffite et al., 2003) can minimize the effect of non-training in the pandemic process (Chen et al., 2020; Zheng et al., 2020; Wang et al., 2020). In this context, it can be said that the training system in accordance with the criteria specified by the researchers is presented with the findings of the study.

\section{Results}

While the training HR values taken from handball players are planned to resemble the training load, it may be suggested that some training structures do not capture the target HR value, that RPE values taken from handball players are subjective, as well as verifying according to the HR value during training.

Keywords: Sport, Team Handball, Covid 19, Home exercises, Interval training.

Öz: Araştırmanın amacını, profesyonel hentbolculara ev ortamında uygulanan yüksek yoğunluklu egzersizlerin saha ortamındaki aerobik kapasiteyle benzerliğini ortaya koymaktır. Araştırma grubunu yaş ortalaması $24,67 \pm 5,71$ yıl, boy uzunluğu $186,69 \pm 6,40 \mathrm{~cm}$ ve vücut ağırlığı $89,63 \pm 8,64 \mathrm{~kg}, 44,94 \pm 28,30$ defa A, genç ve yıldız milli olan 16 erkek hentbolcu oluşturmaktadır. Hentbolcuların ev ortamında uyguladıkları egzersizler sırasında kalp atım sayılarını tespit etmek için S-800 model Polar saat kullanılmıştır. Farklı yoğunluktaki beş hafta süren egzersizler, 4 farklı yoğunluktaki egzersiz gruplarına ayrılmıştır. Hentbolcular ev ortamında yaptıkları egzersizlerin tekrarları sırasında ve bitiminde kalp atım hızları (KAH) ile algılanan zorluk dereceleri (AZD) kaydetmişlerdir. Elde edilen bulgulara göre saha ortamındaki KAHmaks değerleri farklı yoğunluklardaki bazı egzersiz KAH değerleri ile yüksek düzeyde ilişki, AZD maks ile bazı egzersiz AZD değerleri ile orta düzeyde bir ilişki görülmektedir. Sonuç olarak hentbolculardan alınan antrenman KAH değerleri antrenman yüküne benzerlik göstermesi planlanırken bazı antrenman yapılarının hedef KAH değerini yakalamadığı, AZD değerlerinin subjektif olarak alınmasının KAH ile daha anlamlı bir sonuca varılmıştır. Bu tür egzersizi yapacak kişilerin antrenman periyotlamasının belli döneminde bu tür yüklenmeleri koymaları çalışma hedeflerine ulaşmayı etkileyecektir. Ayrıca zorunlu karantina günlerinde profesyonel sporcuların aktif performans çizgilerinden mümkün olduğu kadar uzaklaşmamaları için kişiye özel ve teknikle bağlantılı programlar üzerinde çalışılması önerilir.

Anahtar Kelimeler: Spor, Hentbol, Covid 19, Evde yapılan antrenman, Aralı Antrenman 


\section{Giriş}

Covid 19 pandemisine eskiden "2019 novel coronavirus (2019-nCoV)" olarak bilinen 2019 Yeni Koronavirüs neden olmuştur ve hastalık 11 Şubat 2020'de Dünya Sağlık Örgütü tarafindan resmen COVID-19 olarak adlandırılmıştır. Yapılan çalışmalar, COVID-19'a neden olan virüsün esas olarak enfekte bir kişinin solunum damlacıklarının teması yoluyla bulaştığını göstermiştir. COVID19 salgını, spor da olmak üzere yaşamın tüm alanlarını etkilemiştir (www.who.int, 2020).

Sporun her paydaşı da sporcusundan medya mensuplarına kadar bu pandemiden etkilenmiştir. COVID-19 sürecinde, virüsün bulaş hızını sınırlandırmak için profesyonel ligler de dahil olmak üzere birçok sportif faaliyet askıya alınmıştır. Dünyanın en çok izlenen spor organizasyonu olan Yaz Olimpiyatları bile bir yıl ertelenmiştir. Bu ve benzeri korunma yöntemleri halkın evlerinde kalmasına neden oldu, profesyonel sporcular da kendilerini mesleki faaliyetlerini durdurmakla beraber fiziksel yapılarına yönelik çalışmalarını da azaltmak zorunda kaldılar (Eirale vd., 2020).

Profesyonel sporcular, evlerinde karantina altında oldukları bu süreçte, formlarını koruyabilmek için ev egzersizlerine başvurmuşlardır. Bu deneyim onlar için de bir ilk olmuştur. Tabi ki ev egzersizlerinin saha çalışmalarının yerini tutması beklenmemektedir. Acaba fizyolojik gerekliliklere ne kadar yaklaşılmıştır?

$\mathrm{Bu}$ dönemde antrenmanlara verilen ara Antrenmana özgü uyaranların uzun süreli azalması ya da yok edilmesi olarak açıklanan Detraining (antrenmansızlık) kavramını ortaya çıkartmıştır. Performans azalması detraining süresinin uzunluğuna aktivite türlerinin azalmasına bağlı olarak değişmektedir. Dayanıklılık, kuvvet ve güç özelliklerinde farklılık gösteren detraining kavramının antrenörler tarafından kaçınılmaz bir süreç olarak karşılarına çıkmaktadır.

Ev egzersizleri genellikle vücut ağırlığı egzersizleri ile tasarlanmıştır. Ayrıca bu çalışmada, elit hentbol oyuncularının evlerinde bulunan spor malzemeleri açısından homojenlik sağlanamayacağı için vücut ağırlığı egzersizleri tercih edilmiş̧tir. Vücut ağırlığı ile yapılan egzersizler, kişinin kendi vücudunu, halter, bar veya makine gibi dış direnç kullanmadan bir direnç aracı olarak kullanma prensibine dayanmaktadır (Harrison, 2010). Tipik vücut ağırlığı egzersizlerine şınav, adımlama, mekik, çömelme ve çekişler gibi varyasyonları içermektedir. Kısaca, vücuda ek bir direncin uygulanmadığı herhangi bir hareket, vücut ağırlı̆̆ı egzersizi olarak kabul edilmektedir (ACSM, 2013).

American College of Sports Medicine (ACSM), bir direnç egzersizinin kişinin antrenman seviyesine bağlı olarak, büyük kas gruplarına yönelik, tek tekrar maksimalinin \%60-80 şiddeti aralığında ve 8-12 tekrar sayılarıyla yapılmasını önermektedir. Setler arasında uygun dinlenme aralığı 2-3 dakika aralığındadır. Aynı kas gruplarına yönelik egzersizlerin 2-4 set ve 48 saat arayla yapılması da yine öneriler arasındadır. Eğer vücut ağırlığı ile yapılan bir protokol uygulanıyorsa, haftada 2-3 antrenman yapılabilir. Egzersizlerin seçimi tartışmasız bir antrenman programındaki en önemli değişkendir ve vücut ağırlığını ile yapılan protokoller de farklı değildir. Her bir vücut ağırlığı ile yapılan antrenman içeriğinde en az 8-10 adet çok eklemli fonksiyonel egzersiz olmalıdır. Egzersizlerin seçimi ve sıralaması da program tasarımı ve uygulamasında önemli bir değişkendir (ACSM, 2013). Genel olarak, ACSM egzersiz seçimi ve uygulanması için aşağıdakileri kriterleri önermektedir;

- Gluteus ve quadriceps gibi daha büyük kas grupları, kalf gibi daha küçük kas gruplarından önce çalışılır. Bu, vücudun en iyi şekilde 1sınmasını sağlar ve sonraki egzersizlerin etkinliğini artırabilir.

- Kombine veya çok eklemli egzersizler, izole veya tek eklemli egzersizlerden önce yapılmalıdır. Örnek olarak, parmak ucunda yükselme gibi egzersizlerden önce adımlama setlerini 
yapmak daha uygun olacaktır. $\mathrm{Bu}$, çok eklemli egzersizlerde optimal nöromüsküler uyumunun sağlanmasına yardımcı olur.

- Kas gruplarının istendik toparlanma süresini sağlamak için üst vücutta çekme ile itme egzersizleri birbirini takip etmelidir. Bu şekilde birbirini takip eden egzersizler, kanın tek bir yerde birikmesine izin vermek yerine bir aktif kas grubundan diğerine yönlendirilmesi gerektiğinden, dolaşım sistemi adaptasyonunu da arttırır.

- Sporcu vücut ağırlığı egzersizleri yapıyorsa, egzersizler sırasıyla bir üst vücuda ve bir alt vücuda şeklinde sıralanmalıdır. Bu, yine, egzersiz boyunca kas gruplarının optimal toparlanma süresine izin verir. Uygun toparlanma ile performans ve kuvvet üretimi gelişerek daha fazla adaptasyon sağlanır.

- Pliometrik veya olimpik kaldırış gibi patlayıcı güç egzersizleri, temel kuvvet ve tek eklemli izole egzersizlerden önce yapılmalıdır. Bu egzersizler vücudun koordinasyonunu sağlar. Sporcunun en yüksek performansı ve daha düşük sakatlanma riski için bu egzersizler tam dinlenikken yapilmalidir.

- Optimal eforun ve dikkatin en çok ihtiyaç duyulan kas gruplarına yönlendirilebilmesini sağlamak için, önce daha öncelikli ve çok kuvvet gerektiren egzersizler, sonra da az öncelikli ve az kuvvet gerektiren egzersizler yapılmalıdır.

- Yüksek yoğunluklu egzersizler, düşük yoğunluk egzersizlerinden önce yapılmalıdır (Bushman vd., 2013).

Yukarıda verilen önerilerin dışında Amerikan Spor Hekimleri Birliği ve Dünya Sağlık Örgütü, egzersiz yapacak bireyler için orta şiddet aerobik egzersizler için haftada en az iki ya da daha fazla gün olacak şekilde 150 dakikalık büyük kas grubunu içeren ve 8-12 tekrarlı direnç egzersizleri yapılmas1 önerilmektedir.

Hentbolun doğasındaki enerji tüketimine bakıldığında, modern hentbolun metabolik gerekliklerinde hem aerobik hem de anaerobik enerji yollarının kullanıldığı tespit edilmiştir. Kanıt olarak da 60 dakika süren bir hentbol maçında, oyuncuların 190 defa ritim değişikliğii, 279 defa yön değişikliği, 16 defa maksimal sıçrama yaptığı ve toplam 485 yüksek şiddette hareket gerçekleştirdiği görülmektedir (Bilge vd., 2010; EHF, 2004; Rannau vd., 2001).

$\mathrm{Bu}$ çalışmalar hentbolun aralıklı bir aktivite olduğu iddiasını desteklediği görülmektedir. Hentbola özgü aralıklı aktivite, anaerobik sistemin kullanıldığı yüksek şiddetli aksiyonlar ve aktif toparlanma özelliğine sahip aerobik sistemin kullanıldığı düşük şiddetli hareketleri içerir. Hentbolunun fizyolojik doğası ve interval antrenman (hem aerobik hem de anaerobik) arasındaki ilişkiye bakıldığında, interval antrenmanın hentbolda en önemli antrenman faktörlerinden biri olduğu görülmektedir (Buchheit., 2008).

Müsabakalardaki sportif performansın gereklilikleri dikkate alındığında hentbol, sporcuların optimal aerobik ve anaerobik kapasitelere sahip olmalarını gerektiren interval bir takım sporu olarak görülmektedir (Delamarche, 1987).

İnterval antrenman, farklı toparlanma yöntemleri kullanılarak düşük ya da yüksek şiddetli egzersizlerin dizayn edildiği kondisyonel bir antrenman türüdür. İnterval antrenmanın aralıklı doğası nedeniyle, egzersiz şiddeti ve yapılan toplam iş yükü açısından, sürekli aynı tempoda ve sürede devam eden antrenmandan daha büyük olabilir. $\mathrm{Bu}$ da interval antrenmanı, özellikle hentbol antrenörleri tarafından yaygın olarak kullanılan çok yönlü bir antrenman yöntemi haline getirmektedir. 
İnterval antrenman programları, egzersiz şiddetindeki, yüklenme süresindeki, toparlanma yöntemindeki değişikliklerle hem aerobik hem de anaerobik dayanıklılığı artırmak için de tasarlanabilmektedir (Gorostiaga, 2006; Heyward, 2006).

Hentbol'a özgü interval antrenmanı beş başlıkta tanımlayabiliriz.

1. Sportif performans, hentbol branşının gerekliliklerine göre tanımlanmalıdır.

2. Antrenman yükleri, özellikle hentbola özgü motor becerilerin geliştirilmesi amacıyla tanımlanmalıdır

3. Tekrarlar arasındaki süre bakımından, fizyolojik değişimler normale dönmesi gerçekleşmeden diğer tekrara geçilmesi programlanmalıdır.

kullanılmalıdır.

4. Farklı antrenman yüklerine göre (aerobik ve/veya anaerobik) uygun toparlanma türü

5. Yükün şiddeti, çalışma süresi, dinlenme süresi, türü, tekrar, set, istasyon sayıları ve ayrıca toplam antrenman yükü, hentbol müsabakasının simülasyonuna göre tasarlanmalıdır (Bilge 2013, Heyward, 2006; Baechle ve Earle, 2000; Stone vd., 2007).

Pandemi sürecinde sporcuların egzersiz kısıtlamalarına alternatif olarak sunulabilecek yüksek yoğunluklu egzersizlerin KAH çıktılarının raporlandırılması hedeflenilmiştir.

$\mathrm{Bu}$ bağlamda araştırmanın hipotezini; "Profesyonel düzeyde hentbolculara uygulanan yüksek yoğunluklu egzersizlerin, bazı parametrelere saha ortamındaki etkisi ev ortamında da elde edilecektir" şeklinde oluşturmaktadır.

Alanyazındaki yapılan çalışmalar göz önünde bulundurularak planladığımız çalışmada özellikle hentbolun yapısına özgü kriterler çalışmamızı şekillendirmiştir. Bu kapsamda çalışmanın amacını, profesyonel hentbolculara ev ortamında uygulanan yüksek yoğunluklu egzersizlerin saha ortamındaki aerobik kapasiteyle benzerliğini ortaya koymak oluşturmaktadır.

\section{Yöntem}

\section{Araştırma grubu}

Araştırma grubunu Türkiye Erkekler Süper Ligi'nde yer alan Spor Toto Hentbol takımında oynayan antrenman geçmişi benzer 16 milli hentbolcu oluşturmaktadır. Hentbolcuların yaş, boy uzunluğu ve vücut ağırlıkları ve millilik durumlarına ait betimsel istatistikler Tablo 1'de verilmiştir.

Tablo 1: Hentbolculara Ait Betimsel İstatistik Sonuçları

\begin{tabular}{lcccc}
\hline Değişkenler & En düşük & En yüksek & Ortalama & Ss \\
\hline Yaş (yıl) & 17,38 & 35,64 & 24,67 & 5,71 \\
Boy uzunluğu (cm) & 175 & 196 & 186,69 & 6,40 \\
Vücut ağırlığı (kg) & 79 & 113 & 89,63 & 8,64 \\
Millik durumu (sayı) & 6 & 120 & 44,94 & 28,30 \\
\hline
\end{tabular}

\section{Verilerin Toplanması}

Antrenmanlar, beş hafta ve haftada 4 gün süren 4 farklı egzersizi içerecek şekilde yoğunluklarına göre oluşturuldu. Spor bakanlığının 18.032020 tarihindeki talimatıyla hentbol ligleri durdurulmuştur. $\mathrm{Bu}$ sebeple sporculara evde uygulayabilecekleri bireysel antrenman programları verilmiştir. Covid 19 pandemisinden dolayı parklar ve dışarıdaki antrenman sahaları da kapatılıp kısıtlamalar başladığı için ev egzersizleri 6 Nisan 2020 itibariyle başlatılmış, 12.05.2020 tarihinde ligler tescil edilip, sezon sonlandırıldığı için aradaki beş haftalık sürenin dataları toplanmıştır. Hentbolcular, ev ortamında 5 hafta süren bu egzersizleri düşükten yüksek yoğunluğa doğru verilen periyotlamaya göre uyguladılar. 
Covid-19 Pandemi Sürecinde Evde Uygulanan Yüksek Yoğunluklu Aralıklı Antrenmanlar... 1401

Aşağıda içerikleri verilen farklı yoğunluklardaki egzersizlerin tekrarları sırasında ve bitiminde kalp atım hızları ile algılanan zorluk dereceleri kaydetmişlerdir. Sporcuların $\mathrm{KAH}_{\text {maks }}$ değerleri, sezon içerisinde düzenli olarak yapılan hentbola özgü 30-15 Intermittent Fitness Test ile değerlendirilmiş ve sporcuların tükenme atım hızları, maksimal olarak kabul edilmiştir (Buchheit et al, 2010).

Hentbolculara uygulanan 5 haftalık egzersizlerin ait içerik tablo 2'de verilmiştir.

Tablo 2: Hentbolculara Uygulanan 5 Haftalık Egzersizlere Ait İçerik

\begin{tabular}{|c|c|c|}
\hline 1. Aerobik Aralı Antrenman Programı & \multicolumn{2}{|c|}{ 2. Yaygın Aralı Antrenman Programı } \\
\hline $\begin{array}{l}60 \mathrm{~s} \text { jump rope }+30 \mathrm{~s} \text { isometric core }+30 \mathrm{~s} \\
\text { dynamic core } \\
\mathrm{x} 12 \text { istasyon }=24 \mathrm{dk}\end{array}$ & $\begin{array}{l}30 \mathrm{~s} \text { jogging } \\
30 \mathrm{~s} \text { jumping jacks } \\
30 \mathrm{~s} \text { long jump } \\
30 \mathrm{~s} 1-2-3 \text { step } \\
30 \mathrm{~s} \text { but kicks } \\
30 \mathrm{~s} \text { high knees } \\
30 \mathrm{~s} \text { mummy kicks }\end{array}$ & \\
\hline KAH ölçümü ve $30 \mathrm{~s}$ ara & \multicolumn{2}{|l|}{ KAH ölçümü ve $30 \mathrm{~s}$ ara } \\
\hline $7 \mathrm{dk}$ stretching & \multicolumn{2}{|l|}{$7 \mathrm{dk}$ stretching } \\
\hline $30 \mathrm{~s}$ ara & \multicolumn{2}{|l|}{$30 \mathrm{~s}$ ara } \\
\hline $\begin{array}{l}20 \mathrm{~s} \text { leg work }+10 \mathrm{~s} \text { jump x } 8 \text { istasyon } \\
\text { (Tabata) }\end{array}$ & \multicolumn{2}{|l|}{$\begin{array}{l}30 \text { s hit the floor } \\
30 \text { s power squat } \\
30 \text { s mountain climbing } \\
30 \text { s ski down }\end{array}$} \\
\hline KAH ölçümü ve $30 \mathrm{~s}$ ara & \multicolumn{2}{|l|}{ KAH ölçümü ve $30 \mathrm{~s}$ ara } \\
\hline $\begin{array}{l}20 \mathrm{~s} \text { leg work }+10 \mathrm{~s} \text { jump x } 8 \text { istasyon } \\
\text { (Tabata) }\end{array}$ & $\begin{array}{l}30 \mathrm{~s} \text { scissors run } \\
30 \mathrm{~s} \text { skipping } \\
30 \mathrm{~s} \text { Handball shot } \\
4 \text { push up }+8 \text { sprinting (4 tekrar) } \\
30 \mathrm{~s} \text { swing legs } \\
30 \mathrm{~s} \text { back and fort legs } \\
30 \mathrm{~s} \text { defence touches } \\
30 \mathrm{~s} \text { cross jacks }\end{array}$ & 3 set \\
\hline KAH ölçümü ve $30 \mathrm{~s}$ ara & \multicolumn{2}{|l|}{ KAH ölçümü ve $30 \mathrm{~s}$ ara } \\
\hline $3 \mathrm{dk}$ stretching + Soğuma & \multicolumn{2}{|l|}{$3 \mathrm{dk}$ stretching + Soğuma } \\
\hline
\end{tabular}




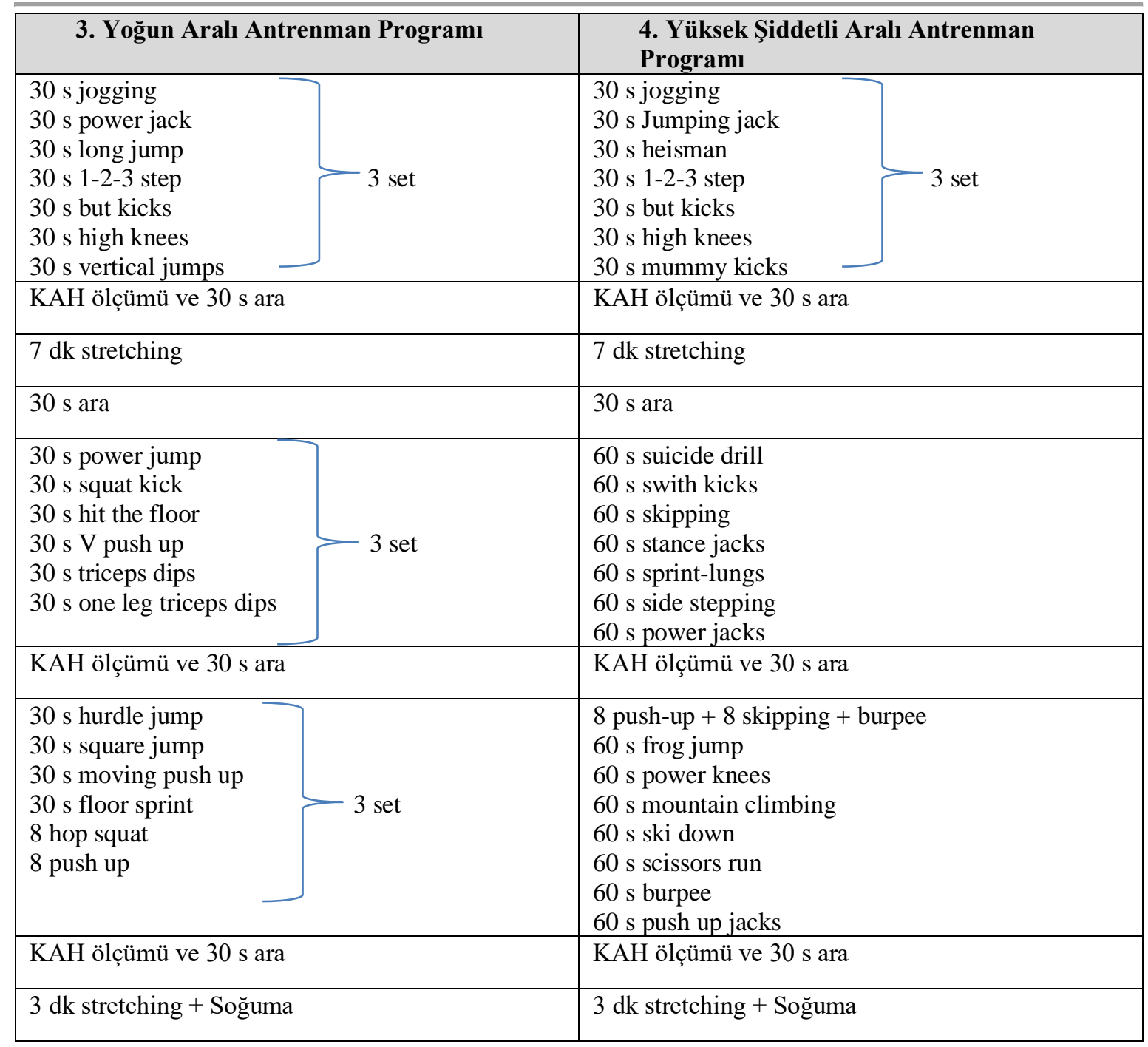

\section{Veri Toplama Araçları}

Hentbolcuların ev ortamında uyguladıkları egzersizler sırasında kalp atım sayılarını tespit etmek için S-800 model Polar saat kullanılmıştır. Polar sistemi birlikte yazılım kalp atım hızı değişkenliğinine ait değerleri türetmek için kullanılır. Wallen vd. (2012) EKG verilerinden elde edilen sonuçları bu sisteme göre karşılaştırdığ çalışmasında geleneksel EKG'lerin yerine tercih edilebileceği sonucuna varmıştır. Algılan zorluk derecelerini tespit etmek için 6-20 dereceli Borg skalası kullanılmıştır.

\section{Verilerin Analizi}

Araştırma grubunu oluşturan hentbolculardan farklı antrenman yüklerinden elde edilen KAH ve AZD değerleri maksimum KAH ve AZD'yi yordaması için öncelikle verilerin dağılımı Shapiro Wilk testi ile analiz edilip normallik varsayımın sağlanması durumunda regresyon analizi uygulandı. Hentbolcuların yaş, boy uzunluğu ve vücut ağırlığı özelliklerine ait betimsel istatistikler elde edildi. İstatistiksel analizler için SPSS 25.0 paket programı kullanıldı. Anlamlılık düzeyi için $\mathrm{P}<0,05$ alındı.

\section{Bulgular}

Bu bölümde farklı yoğunluklarda uygulanan egzersizlerin maksimum değerleri yordamında ilişkin sonuçlar tablo ve yorumlarıyla verilmiştir. 
Covid-19 Pandemi Sürecinde Evde Uygulanan Yüksek Yoğunluklu Aralıklı Antrenmanlar... 1403

Üst ligde uygulanan farklı yoğunluklardaki antrenmanların KAHmaks değerleri (Xort=189,63 $\pm 5,51 \mathrm{atım} / \mathrm{dk}$ ) yordanmasına ilişkin regresyon analiz sonuçları Tablo 2'de verilmiştir.

Tablo 2: KAHmaks Yetisinin Yordanmasına İlişkin Regresyon Analizi Sonuçları.

\begin{tabular}{|c|c|c|c|c|c|c|c|}
\hline Değişken & B & SHata & $\boldsymbol{\beta}$ & $\mathbf{t}$ & $\mathbf{p}$ & İkili & Kismi \\
\hline Sabit (KAHmaks) & 94,380 & 21,653 & & 4,359 & ,001 & & \\
\hline $\begin{array}{l}\text { Aerobik antrenman } \\
(X=140,95 \pm 14,02 \text { atım/dk })\end{array}$ & 184 & ,071 & ,468 & 2,583 & 025, & ,768 & ,614 \\
\hline $\begin{array}{l}\text { Yaygin aralı antrenman } \\
(\mathrm{X}=164,61 \pm 6,06 \mathrm{at} 1 \mathrm{~m} / \mathrm{dk})\end{array}$ & ,370 & ,665 & ,407 &, 556 & ,590 &, 779 & ,165 \\
\hline $\begin{array}{l}\text { Yoğun aralı antrenman } \\
(X=166,80 \pm 6,06 \mathrm{atı} / \mathrm{dk})\end{array}$ & 619, & 629, & ,681 & ,983 & ,347 & ,796 & ,284 \\
\hline $\begin{array}{l}\text { Yüksek yoğunluklu aralı } \\
(X=169,70 \pm 6,81 \mathrm{atım} / \mathrm{dk})\end{array}$ &,- 558 & ,238 &,- 690 & $-2,344$ & ,039 &, 583 &,- 577 \\
\hline$F_{(4-11)}=12,234$ & $\mathrm{P}=, 000$ & & & & & & \\
\hline $\mathrm{R}=, 904$ & $\mathrm{R}^{2}=, 816$ & & & & & & \\
\hline
\end{tabular}

Tablo 2 incelendiğinde hentbolculardan elde edilen farklı yoğunluklardaki antrenmanlara ait KAH değerleri birlikte Maksimum KAH ile yüksek düzeyde pozitif ve istatistiksel olarak anlamlı bir ilişki görülmektedir $\left(\mathrm{R}=, 904, \mathrm{R}^{2}=, 816, \mathrm{P}<0,05\right)$. Adı geçen 4 değişken birlikte Maks KAH değerindeki toplam varyansın yaklaşık \% 82'ini açıklamaktadır. Bir başka değişle antrenmanlardaki KAH ile KAHmaks arasında yüksek oranda benzerlik görülmektedir.

Standardize edilmiş regresyon katsayısı ( $\beta$ ) göre yordayıcı değişkenlerin KAHmaks yetisi üzerindeki göreli önem sırası, yüksek yoğunluklu, yoğun aralı ve aerobik ve yaygın aralı şeklindedir.

Regresyon katsayılarının anlamlılığına ilişkin T-Testi sonuçlanı incelendiğinde ise yüksek yoğunluklu aralı ve aerobik antrenman KAH değerleri KAHmaks yetisi üzerinde anlamlı bir yordayıcı olduğu görülürken, yaygın aralı ve yoğun aralı antrenmanlardan elde edilen KAH üzerine anlamlı etkisi olmadığı görülmektedir. Bu bulguya göre Maks KAH değerlerine en anlamlı benzerliği aerobik ve yüksek yoğunluklu aralı antrenmanlardan elde edilen KAH değerleri göstermektedir.

Üst ligde uygulanan farklı yoğunluklardaki antrenmanlardan elde edilen AZD ile Maksimum testten elde edilen AZD'nin (Xort=9,45, \pm 52 birim) yordanmasına ilişkin regresyon analiz sonuçları Tablo 3'de verilmiștir.

Tablo 3: Azdmaks Yetisinin Yordanmasına İlişkin Regresyon Analizi Sonuçları.

\begin{tabular}{|c|c|c|c|c|c|c|c|}
\hline Değişken (AZDmaks) & B & SHata & $\beta$ & $\mathbf{t}$ & $\mathbf{p}$ & İkili & kısmi \\
\hline Sabit & 13,093 & 2,256 & & 5,803 & ,000 & & \\
\hline $\begin{array}{l}\text { Aerobik antrenman } \\
(\mathrm{X}=5,75 \pm, 58 \text { birim })\end{array}$ &,- 512 & ,300 &,- 572 & $-1,706$ & ,116 &,- 447 &,- 457 \\
\hline $\begin{array}{l}\text { Yaygin aralı antrenman } \\
(\mathrm{X}=7,13 \pm, 50 \text { birim })\end{array}$ &,- 169 & ,584 &,- 163 &,- 289 & ,778 &,- 258 &,- 087 \\
\hline $\begin{array}{l}\text { Yoğun aralı antrenman } \\
(\mathrm{X}=8,25 \pm, 68 \text { birim })\end{array}$ & ,452 &, 511 & ,598 & ,885 & ,395 &,- 189 & ,258 \\
\hline $\begin{array}{l}\text { Yüksek yoğunluklu aralı } \\
(\mathrm{X}=8,50 \pm, 63 \text { birim })\end{array}$ &,- 373 & ,356 &,- 457 & $-1,050$ & ,316 &,- 204 &,- 302 \\
\hline $\begin{array}{l}\mathrm{F}_{(4-11)}=1,062 \\
\mathrm{R}=, 528\end{array}$ & $\begin{array}{l}\mathrm{P}=, 420 \\
\mathrm{R}^{2}=, 279\end{array}$ & & & & & & \\
\hline
\end{tabular}


Tablo 3 incelendiğinde hentbolculardan elde edilen farklı yoğunluklardaki antrenmanlara ait AZD değerleri birlikte maksimum düzeyde uygulanan AZD ile orta düzeyde pozitif bir ilişki görülmektedir. Ancak bu ilişki istatistiksel olarak anlamlı görülmemektedir $\left(\mathrm{R}=, 528, \mathrm{R}^{2}=, 279\right.$, $\mathrm{P}>0,05)$. Adı geçen 4 değişken birlikte AZDmaks değerindeki toplam varyansın yaklaşık \%28'ini açıklamaktadır. Bir başka değişle antrenmanlarda belirtilen AZD ile AZDmaks arasında düşük oranda benzerlik görüldüğü, sporcuların AZD değerlerini belirtmede antrenman yüküyle uyumlu cevap vermedikleri söylenebilir.

Standardize edilmiş regresyon katsayısı $(\beta)$ göre yordayıcı değişkenlerin AZDmaks yetisi üzerindeki göreli önem sırası, yoğun aralı, aerobik, yüksek yoğunluklu ve yaygın aralı şeklindedir.

Regresyon katsayılarının anlamlılığına ilişkin T-Testi sonuçları incelendiğinde ise hentbolculardan alınan antrenman AZD değerlerinin AZDmaks üzerinde anlamlı etkisi olmadığ 1 görülmektedir. $\mathrm{Bu}$ bulguya göre AZDmaks antrenmanlarda alınan AZD ile benzeşmediği belirlenmiştir.

\section{Tartışma}

Fiziksel kapasitenin korunması sporcu için temel bir gerekliliktir. Özellikle, takım sporları sporcular için, aerobik güç ve kas gücü hem iyi bir düzeyde korumak performansı değişmeden korumak için temel bir ön koşuldur. Antrenman fizyolojik adaptasyon geri dönüşümlü bir süreçtir. Gerçekten de fizyolojik adaptasyonun pek çok yönü uzun süreli hareketsizlik döneminde kaybolmuştur (Mallo, 2015). Hız ve maksimum kuvvet yetisi dayanıklılık ve kuvvette devamlılığa göre daha fazla fiziksel kapasite için kayıp oluşmaktadır. Genel olarak toplam hareketsizliğin her haftası için \%10'a varan genel bir kayıp olduğu kabul edilmektedir (Varandas vd., 2017). Çalışmada bu antrenmansızlık etkisinin az oranda olması kapsamında yapılan interval çalışmaların, özellikle saha ortamında elde edilen KAHmaks değerine yakın etkilerde uyarılar oluşturduğu görülmektedir. $\mathrm{Bu}$ kapsamda antrenman periyotlamasında yoğun yüklenmelerin verilmesi ön plana çıkmaktadır.

Geçiş dönemine benzer bir süreç olarak düşünülecek pandemi dönemin sonrasında açıkçası, oyuncuların antrenman sıklığı ve yoğunluğundaki hızlı artışa tahammül edebilmek için fitness seviyelerini korumaları, aynı zamanda yaralanma riskini en aza indirmeye çalışması çok önemlidir (Gabbett, 2007). Bu literatür bilgisini destekler nitelikte çalışmada özellikle AZD değerlerinin antrenman yükü ile uyuşmadığı bir başka deyişle yüksek nabızlı antrenmanların sporcuda oluşturduğu etkinin uyumsuz olduğu belirlenmiştir. Bu sonuç bize AZD ve benzeri antrenman iç yüklerinin sporculara öğretilmesi gerektiğini göstermektedir.

Özellikle 20 gün veya daha büyük bir süre içinde yüksek yoğunluklu aerobik kapasitede (VO2max) önemli bir azalmaya neden olduğu belirtilmektedir. Bu nedenden dolayı, sezon dış1 dönemden sonra sporcuların sezon içinde özellikle ilk haftalarında yüksek antrenman hacmi ve yoğunluğunu tolerans göstermekte güçlük çekebilirler (Silva vd., 2016). Hansen vd. (2018)'nin belirttiği gibi kardiyo tarzı egzersizlerde dikkat edilmesi gereken $60 \mathrm{dk}$ 'llk yüklenme önerilerinin yanı sıra çalışmaların KAH'nın \%80'ine denk gelmesi (McMullen vd., 2018) hem aerobik hem de anaerobik laktik asit sisteminin baskın olduğu antrenman aralıklı veya aralıklı antrenmanlar (Dufour vd., 2006; Billat vd., 2000; Laffite vd., 2003) pandemi sürecindeki antrenmansızlık etkisini aza indirebilmektedir (Chen vd., 2020; Zheng vd., 2020; Wang vd., 2020). Bu bağlamda araştırmacıların belirttiği kriterlere uygun antrenman sistematiğinin çalışmanın bulgularıyla ortaya konulduğu söylenebilir.

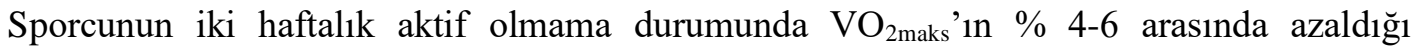
görülmektedir. Bu performans düşüklüğü özellikle yüksek antrenmanlı sporcularda daha yoğun görülmektedir. Antrenmansızlık döneminde maksimal aerobik kapasitenin 3-8 hafta içerisinde \% 20 azalmaya neden olduğu ve bu sürenin uzamasıyla düşüş değerinin arttı̆̆ belirtilmektedir. Antrenmansız sürecindeki bir sporcunun 2-4 hafta içerisinde kalp atım volümünde \%12'lik, oksidatif 
enzimlerde düşüş yaşandığı belirlenmiştir. İki hafta antrenmansızlık döneminde skuat $(\% 0,9)$ ve bench pres $(\% 1,7)$ değerlerinde düşüşler bulunduğu, maksimal izometrik diz ekstansiyon kuvvet değerinde \%3'lük azalma görülmektedir. Bir başka çalışmada 4 haftalık antrenmansızlık sürecinde skuat kuvvet değerinde \%6'lık, bench pres değerinde ise \%9'luk azalma belirlenmiştir (Cal Abad vd., 2015; Delecluse, 1995).

Cal Abad vd. (2015) ile Delecluse (1995)'in belirttiği antrenmansızlık etkilerinin özellikle dayanıklılık ve kuvvet yetilerindeki azalışın araştırmamızdaki yüksek yoğunluklu ve baskın olarak kuvvetin çalışılması yönündeki önerilerimizi destekler nitelikte olduğu belirlenmiştir.

\section{Sonuç}

Hentbolculardan alınan antrenman KAH değerleri antrenman yüküne benzerlik göstermesi planlanırken bazı antrenman yapılarının hedef KAH değerini yakalamadı̆̆ı, AZD değerlerinin subjektif olarak alınmasının KAH ile daha anlamlı bir sonuca varılmıştır.

$\mathrm{Bu}$ tür egzersizi yapacak kişilerin antrenman periyotlamasının belli döneminde bu tür yüklenmeleri koymaları çalışma hedeflerine ulaşmayı etkileyecektir. Ayrıca zorunlu karantina günlerinde profesyonel sporcuların aktif performans çizgilerinden mümkün olduğu kadar uzaklaşmamaları için kişiye özel ve teknikle bağlantılı programlar üzerinde çalışılması önerilir.

\section{Kaynakça}

American College of Sports Medicine. (2013). ACSM's guidelines for exercise testing and prescription. Lippincott Williams \& Wilkins.

Baechle TR, Earle RW. (2000). Essentials of Strength Training and Conditioning. China, Human Kinetics.

Bilge M, Sevim Y, Ersöz G. (2010). An investigation of the relationship between peak anaerobic power-capacity, body composition and heart rate in Turkish national senior handball players. Dirim Medical Journal, 85 (4), 152-165.

Bilge, M.. (2013). Interval training specific to handball and training programme designs. World $\begin{array}{llll}\text { Applied } & \text { Sciences } & \text { Journal. } & \text { 25(7), }\end{array}$ http://dx.doi.org/10.5829/idosi.wasj.2013.25.07.13363

Billat VL, Slawinski J, Bocquet V, Demarle A, Lafitte L, Chassaing P, et al. (2000). Intermittent runs at the velocity associated with maximal oxygen uptake enables subjects to remain at maximal oxygen uptake for a longer time than intense but submaximal runs. Eur J Appl Physiol. 81(3):188-196. http://dx.doi.org/10.1007/s004210050029

Buchheit M. (2008). The 30-15 intermittent fitness test: accuracy for individualizing interval training of young intermittent sport players. J Strength Con Research. 22 (2), 365-374. http://dx.doi.org/10.1519/JSC.0b013e3181635b2e

Buchheit, M., Mendez-Villanueva, A., Quod, M., Quesnel, T., \& Ahmaidi, S. (2010). Improving acceleration and repeated sprint ability in well-trained adolescent handball players: speed versus sprint interval training. International Journal of Sports Physiology and Performance. 5(2), 152-164. http://dx.doi.org/10.1123/ijspp.5.2.152

Bushman BA, Battista R, Swan P, Ransdell L, Thompson WR. (2013). ACSM's Resources for the Personal Trainer. 4th ed. Philadelphia (PA): Wolters Kluwer Health Adis.

Cal Abad CC, Cuniyochi R, Kobal R, Gil S, Kitamura K, Nakamura FY. et al. (2015). Effect of detraining on body composition, vertical jumps ability and sprint performance in young elite soccer players. Andaluza J Sports Med. http://dx.doi.org/10.1016/j.ramd.2015.03.003 
Chen P, Mao L, Nassis GP, Harmer P, Ainsworth BE, Li F. (2020). Wuhan coronavirus (2019$\mathrm{nCoV}$ ): The need to maintain regular physical activity while taking precautions. J Sport Health Sci. 9(2):103-104. http://dx.doi.org/10.1016/j.jshs.2020.02.001

Chodzko-Zajko WJ, Proctor DN, Singh MAF, Minson CT, Nigg CR, Salem GJ, et al. (2009). Exercise and physical activity for older adults. Med Sci Sport Exer. 41(7): 1510-30. http://dx.doi.org/10.1249/MSS.0b013e3181a0c95c

Delamarche P., Gratas, A., Beillot, J., Dassonville, J., Rochcongar, P., Lessard, Y. (1987). Extent of lactic anaerobic metabolism in handballers. Int $\mathrm{J}$ Sport Med. 8, 55-59. http://dx.doi.org/10.1055/s-2008-1025641

Delecluse C, Van Coppenolle H, Willems E, Van Leemputte M, Diels R, Goris M. (1995). Influence of high-resistance and high-velocity training on sprint performance. Med Sci Sports Exerc. 27:1203-1209. http://dx.doi.org/10.1249/00005768-199508000-00015

Dufour SP, Ponsot E, Zoll J, Doutreleau S, Lonsdorfer-Wolf E, Geny B, et al. (2006). Exercise training in normobaric hypoxia in endurance runners. I. Improvement in aerobic performance $\begin{array}{llll}\text { capacity. J Appl Apr;100(4):1238-48. } & \text { J }\end{array}$ http://dx.doi.org/10.1152/japplphysiol.00361.2005.

EHF (2004). Youth Coaches' Course: Development of physical Condition, Czechia, 1-12.

Eirale C, Bisciotti G, Corsini A, Baudot C, Saillant G, Chalabi H. (2020). Medical recommendations for home-confined footballers' training during the COVID-19 pandemic: from evidence to practical application. Biology of Sport. 37(2). https://doi.org/10.5114/biolsport.2020.94348

Gabbett TJ, Domrow N. (2007). Relationships between training load, injury, and fitness in sub-elite collision sport athletes. J Sports Sci. 25(13):1507-1519. http://dx.doi.org/10.1080/02640410701215066

Gorostiaga EM et al. (2006). Effect of entire season on physical fitness changes in elite male handball players. Med Sci Sports Exerc. 38, 357-366. http://dx.doi.org/10.1249/01.mss.0000184586.74398.03.

Hansen D, Niebauer J, Cornelissen V, Barna O, Neunhäuserer D, Stettler C, et al. (2018). Exercise Prescription in Patients with Different Combinations of Cardiovascular Disease Risk Factors: A Consensus Statement from the EXPERT Working Group. Sports Med. Aug;48(8):1781-1797. http://dx.doi.org/10.1007/s40279-018-0930-4

Harrison JS. Bodyweight training: a return to basics. Strength Cond J. 2010;32(2): 52-5.

Heyward VH. (2006). Advanced Fitness Assessment and Exercise Prescription, 5th ed, Human Kinetics, USA, 2006.

https://www.who.int/emergencies/diseases/novel-coronavirus-2019/training/simulation-exercise

Laffite LP, Mille-Hamard L, Koralsztein JP, Billat VL. (2003). The Effects of Interval Training on Oxygen Pulse and Performance in Supra-threshold Runs. Arch Physiol Biochem. 111(3):202-210. http://dx.doi.org/10.1076/apab.111.3.202.23455

Mallo J. (2015). Complex football. From Seirullos' structured training to frad's tactical periodization. Javier Mallo Sainz Editions.

McMullen CW, Harrast MA, Baggish AL. (2018). Optimal running dose and cardiovascular risk. Curr Sports Med Rep.17(6):192-198. http://dx.doi.org/10.1249/JSR.0000000000000491

Patel K. (2014). The Complete Guide to Bodyweight Training. London, UK: Bloomsbury Publishing PLC;p: 192 
Covid-19 Pandemi Sürecinde Evde Uygulanan Yüksek Yoğunluklu Aralıklı Antrenmanlar... 1407

Rannau F et al. (2001). Physiological profile of handball players. J Sports Med Physiol Fitness. 41, 349-353.

Silva JR, Brito J, Akenhead R, Nassis GP. (2016). The Transition Period in Soccer: A Window of Opportunity. Sports Med.46(3):305-313. http://dx.doi.org/10.1007/s40279-015-0419-3

Stone MH, Stone M, Sands WA. (2007). Principles and Practice of Resistance Training, USA, Human Kinetics.

Varandas F, Medina D, Gomez A, Della Villa S. (2017). Late rehabilitation on the field. In: Injury and health problem in football. Springer Berlin Heidelberg; 2017. p. 571-9.

Walle'n MB, Hasson, D, Theorell T, Canlon B, Osika W. (2012). Possibilities and limitations of the polar RS800 in measuring heart rate variability at rest. Eur J Appl Physiol. 2012; 112(3):1153- 1165. http://dx.doi.org/10.1007/s00421-011-2079-9

Wang L-S, Wang Y-R, Ye D-W, Liu Q-Q. (2020). A review of the 2019 Novel Coronavirus (COVID-19) based on current evidence. Int J Antimicrob Agents. Mar 19:105948. http://dx.doi.org/10.1016/j.ijantimicag.2020.105948

Zheng YY, Ma YT, Zhang JY, Xie X. (2020). COVID-19 and the cardiovascular system. Nat Rev Cardiol. Mar 5:1-2. http://dx.doi.org/10.1038/s41569-020-0360-5 